\title{
TRÁFICO INTERNACIONAL DE PESSOAS
}

\author{
Antônio Carlos Alves de OLIVEIERA ${ }^{1}$ \\ Wagner Saraiva Ferreira Lemgruber BOECHAT ${ }^{2}$ \\ Edson Câmara de Drumond ALVES JÚNIOR ${ }^{3}$
}

Recebido em: 15/09/2015 - Aprovado em: 23/06/2016 - Disponibilizado em: 30/07/2016

\begin{abstract}
Resumo: O principal objetivo do presente trabalho, é promover um debate sobre um tema que está em evidencia na atualidade, que seria o tráfico de pessoas, com enfoque especial no tráfico de mulheres. Como objetivo específico, pretende-se relatar como a violência e o abuso contra a dignidade humana são presentes, mesmo em uma época onde se proliferam as leis de proteção a pessoa, estas não são totalmente efetivas. Para o desenvolvimento do trabalho, adotou-se como metodologia o estudo bibliográfico, sendo possível concluir que o tráfico de pessoas esta intimamente ligados a questões sócio culturais, ao qual a política e a própria sociedade, muitas vezes é complacente com tal situação, e as políticas de combate ao tráfico de seres humanos, são um passo importante, mas, não totalmente.
\end{abstract}

Palavras-chave: Violência; Tráfico de pessoas; Legislação; mulher; brasil.

Abstract: The main objective of this work is to promote a debate on a topic that is in evidence today, trafficking of persons, with special focus on women trafficking. As a specific objective, it's intend to report how violence and abuse against human dignity are present, even in an age where proliferate protection laws the person, these are not fully effective. For the development work, it adopted as methodology the bibliographical study, which concluded that human trafficking are closely linked to socio-cultural issues, to which politics and society itself, is often complacent about this situation, and to combat trafficking in human beings policies are an important step, but not totally.

Keywords: Violence; Trafficking in persons; Legislation; Women; Brazil.

\footnotetext{
${ }^{1}$ Bacharelando em Direito pela UninCor.

2 Advogado, consultor Ambiental, professor de Direito na Universidade Vale do Rio Verde e Faculdade de São Lourenço. Graduado em Direito pela Faculdade de São Lourenço, pós-graduado em Direito Público pela Faculdade de São Lourenço, em Direito Tributário pela Fundação Getúlio Vargas, Direito Ambiental e Urbanístico pelo Centro Anhanguera de Promoção e Educação Social e mestre em Direito - linha Constitucionalismo e Democracia - pela Faculdade de Direito do Sul de Minas Gerais. E-mail: wagnersflb@gmail.com

${ }^{3}$ Advogado, professor de Direito na Universidade Vale do Rio Verde. E-mail: edsondrummondjr@hotmail.com 989 


\section{INTRODUÇÃO}

O principal objetivo do presente trabalho é promover um debate sobre um tema que está em evidencia na atualidade, o tráfico de pessoas, com enfoque especial no tráfico de mulheres.

Como objetivo específico, pretende-se relatar como a violência e o abuso contra a dignidade humana são presentes, mesmo em uma época na qual se proliferam as leis de proteção às pessoas.

Hoje, verifica-se que a sociedade muitas vezes prefere ignorar uma realidade que está evidente, como o tráfico de pessoas voltado para o trabalho forçado ou para o turismo sexual, no qual as vítimas, em busca de uma situação melhor, acabam em locais como bordeis, sendo sexualmente exploradas, ou, muitas vezes, executando trabalhos análogos a escravidão.

Desse modo, esse trabalho aborda por meio de uma sucinta analise, os aspectos relativos ao tema, relatando como atualmente é realizado o tráfico de pessoas para fins de turismo sexual ou trabalho forçado, além de abordar os seus principais agentes envolvidos, realizando uma revisão de literatura sobre os trabalhos que hoje são realizados por organizações internacionais como forma de combate e prevenção desse mal, tão comum na atualidade.

Para o desenvolvimento do trabalho, adotou-se como metodologia o estudo bibliográfico. Quanto à abordagem, optou-se por uma análise teórica, ancorada nos seguintes procedimentos: pesquisa bibliográfica a partir da revisão de literatura sob a temática abrangendo enciclopédias, coleções, livros, artigos, revistas, como Jusnavegandi, e jornais on-line, retirados de bibliotecas digitais de instituições como: USP E PUC e a própria doutrina jurídica, enquanto a pesquisa documental valeu-se de informações colhidas de trabalhos públicos e privados.

As publicações encontradas foram organizadas como pesquisa e de revisão e, posteriormente, categorizadas. A revisão bibliográfica foi feita mediante análise acurada da literatura aplicada, extraindo-se os pontos relevantes ao tema explicitado, com o fim de justificar as ações apresentadas.

Apesar da existência de outras pesquisas envolvendo o tema, há ainda, fatos a serem destacados na problemática deste estudo. Dessa forma espera-se que este trabalho possa contribuir para o preenchimento dessa lacuna, servindo de base para outros pesquisadores que se interessem pelo assunto. 


\section{BREVE HISTÓRICO}

De acordo com Shecaria e Silveira (2002) a mais antiga referência histórica do tráfico de pessoas está sem qualquer dúvida no tráfico negreiro. $\mathrm{O}$ Brasil colônia sempre manteve a escravidão, sendo o último pais da América a aboli-la; decisão essa devido em grande parte pelo desinteresse inglês no tráfico, o que se dera já no início do séc. XIX, pois que tinham grandes interesses no mercado consumidor na América do Sul.

Alves (2004) também destaca que na idade antiga, com o advento da escravidão, passou a ser corriqueiro e até mesmo normal o homem, desprovido de riqueza, ser considerado ou ser colocado em condições de escravidão, consequentemente retirada a sua cidadania. Afirma ainda, que as guerras, expansão de povos dominadores e a necessidade de conquistas faziam com que o trabalho fosse identificado como algo penoso, árduo. A mão-de-obra, se não escrava, pessimamente remunerada, mesmo porque se a própria definição de trabalho advém da concepção de tortura ou equipamento de tortura, o que representava bem essa ideia de castigo ou pena. Os homens que detinham o poder e dominavam outros homens tinham como pensamento que o trabalho era coisa a ser realizada pelos escravos.

Relata Sussekind et. al (1984) que naquele tempo, a escravidão era considerada coisa justa e necessária, tendo Aristóteles, complementando a informação anterior, afirmado que, para conseguir cultura, era necessário ser rico e ocioso e que isso não seria possível sem a escravidão. A existência da escravidão nos tempos medievais era marcada pelo grande número de prisioneiros feitos especialmente entre os bárbaros e infiéis senhores feudais que vendiam-nos como escravos nos mercados de onde seguiriam para o Oriente Próximo.

Sob vários pretextos e títulos, a escravidão dos povos mais fracos prosseguiu por vários séculos; em 1452 o Papa Nicolau autorizava o rei de Portugal a combater e reduzir à escravidão todos os muçulmanos, e em 1488 o rei Fernando, o Católico, oferecia dez escravos ao Papa Inocêncio VIII, que os distribuía entre cardeais. Mesmo com a queda da Constantinopla em 1453, a escravidão continuou e tomou incremento com o descobrimento da América. Os espanhóis escravizavam os indígenas das terras descobertas e os portugueses não só aqueles, como também faziam incursões na costa africana, conquistando escravos para trazer para as terras do Novo Continente. 
Damásio de Jesus (2002) relata que o tráfico de seres humanos faz parte da nossa história. Os navios negreiros transportaram, durante 300 anos, milhões de pessoas - homens, mulheres e crianças para o trabalho agrícola, que se estendia à servidão doméstica, à exploração sexual e às violações físicas

\section{SITUAÇÃO ATUAL}

Atualmente, milhares de pessoas cruzam o oceano em busca de um sonho ou de melhores condições de vida, fugindo das guerras, da fome, da pobreza de suas nações, da perseguição religiosa e da violência.

É certo que se, por um lado, algumas pessoas estão dispostas a assumir o risco de cair nas mãos de traficantes para melhorarem as suas condições de vida, por outro, existe nos países industrializados uma tendência preocupante à utilização de mão-de-obra barata e clandestina, bem como à exploração de mulheres e crianças para fins de prostituição e pornografia.

As mulheres são particularmente vulneráveis ao tráfico de seres humanos devido à pobreza, à sobreposição do homem, à falta de possibilidades de educação e de emprego nos seus países de origem (RIBEIRO, 2006).

\section{TRÁFICO DE PESSOAS}

A pesquisa realizada pela Aliance Against Traffiking In Womem - GAATW (1997), sobre trafico e direitos Humanos afirma que recentemente a comunidade internacional reconheceu a necessidade de se expandir a compreensão do tráfico de pessoas, para incluir fatos que antes eram desprezados, pois suas características históricas encontravam-se ultrapassadas, mal definidas e não relacionadas às atuais realidades do movimento e tráfico de pessoas, sua natureza, extensão e causas.

O Protocolo das Nações Unidas contra o Crime Organizado Transnacional Reativo à Prevenção, Repressão e Punição ao Tráfico de Pessoas, especialmente Mulheres e Crianças, é o atual documento da Organização das Nações Unidas a tratar do tráfico de seres humanos. Em comparação aos documentos internacionais anteriores que abordaram esse tema, o Protocolo de Palermo, como também é conhecido, destaca-se por apresentar a primeira definição desse delito (PISCITELLI, 2001).

As definições limitavam-se a descrever o tráfico apenas como atividade de migração facilitada à exploração da prostituição e como movimento de pessoas através de ameaça ou uso de força, coação ou violência, deixando de incluir, por 
exemplo, o casamento forçado e o trabalho forçado (NOGUEIRA, 2000).

Segundo o Protocolo de Palermo, em seu artigo 3:

a) A expressão 'tráfico de pessoas' significa o recrutamento, o transpor -te, a transferência, o alojamento ou o acolhimento de pessoas, recorrendo à ameaça ou uso da força ou a outras formas de coação, ao rapto, à fraude, ao engano, ao abuso de autoridade ou à situação de vulnerabilidade ou à entrega ou aceitação de pagamentos ou benefícios para obter o consentimento de uma pessoa que tenha autoridade sobre outra para fins de exploração.

A exploração incluirá, no mínimo, a exploração da prostituição de outrem ou outras formas de exploração sexual, o trabalho ou serviços forçados, escravatura ou práticas similares à escravatura, a servidão ou a remoção de órgãos.

b) $\mathrm{O}$ consentimento dado pela vítima de tráfico de pessoas tendo em vista qualquer tipo de exploração descrito na alínea a) do presente Artigo será considerado irrelevante se tiver sido utilizado qualquer um dos meios referidos na alínea a);

c) $\mathrm{O}$ recrutamento, $\mathrm{o}$ transporte, a transferência, o alojamento ou o acolhimento de uma criança para fins de exploração serão considerados 'tráfico de pessoas' mesmo que não envolvam nenhum dos meios referidos da alínea a) do presente Artigo;

d) O termo "criança" significa qualquer pessoa com idade inferior a dezoito anos.

Nesse sentido, redes globais de OSCs (Organizações das Sociedade Civis) integradas à iniciativa de proteção as vítimas do tráfico, elaboraram Padrões de Direitos Humanos (PHD) para o tratamento de pessoas traficadas, que trazia a seguinte definição:

Todos os atos ou tentativas
presentes no recrutamento,
transporte, dentro ou através
das fronteiras de um país,
compra, venda, transferência,
recebimento ou abrigo de uma
pessoa envolvendo o uso do
engano, coerção (incluindo o
uso ou ameaça de uso de força
ou abuso de autoridade) ou
dívida, com o propósito de
colocar ou reter tal pessoa,
seja por pagamento ou não,
em servidão involuntária
(domestica, sexual ou
reprodutiva) em trabalho
forçado ou cativo, ou em
condições similares à
escravidão, em uma
comunidade diferente daquela
em que tal pessoa viveu na
ocasião do engano, da coerção
ou da dívida inicial (GAATW,
1997).

A definição apresentada pelo

Protocolo de Palermo trouxe significativos avanços. Inicialmente, é importante destacar que o documento faz referência ao tráfico de pessoas, e não mais apenas de mulheres, como se observa nos anteriores. Essa mudança demonstra a ideia que se tem de que tanto homens como mulheres podem ser traficados (GALLAGHER, 2002).

A definição do (PHD) procura focar claramente os elementos restritivos ao crime, a fim de distinguir o tráfico de outros delitos semelhantes. Conforme este 
conceito, o grupo pôde envolver um individuo ou um grupo de indivíduos, começando o ilícito com o aliciamento e terminando com a pessoa que explora a vítima, que a compra e a mantém em regime de escravidão ou a submete a condições similares à escravidão, ao trabalho forçado ou a outras formas de servidão (GAATW, 1997).

Ademais, o tráfico está definido como um processo que ocorre com várias etapas distintas, conforme se depreende da leitura do artigo 3. Esse processo inclui o recrutamento, o transporte, a transferência, o alojamento ou o acolhimento de pessoa, utilizando-se de qualquer dos meios coercitivos descritos, que podem ocorrer de diversas formas, envolvendo várias pessoas em suas diferentes etapas, tendo como finalidade a exploração (ALMEIDA, 2004).

O tráfico internacional passa a ser visto como aquele que ocorre não só quando se cruza a fronteira entre países, mas no ato de se mover uma pessoa de uma região para outra, até mesmo dentro dos limites de um único país, observando que o consentimento da vítima em seguir viagem não exclui a culpabilidade do traficante ou do explorador, nem limita o direito a vítima de proteção oficial (GAATW, 1997).
Na definição do Protocolo, o tráfico de seres humanos ocorre com a finalidade da exploração de alguém em diversos setores do mercado de trabalho. Essa exploração se refere às condições de trabalho às quais as pessoas são submetidas e a como se desenvolve a relação trabalhista, muitas vezes se submetendo o trabalhador a horas extenuantes de atividade, desenvolvida de modo forçado, em condições inadequadas, restringindo sua liberdade de locomoção, recebendo baixo ou nenhum pagamento e sem a observância da legislação trabalhista (ABREU, 2001).

Segundo esta definição, observase que o requisito central do tráfico é a presença do engano, da coerção, da dívida e do propósito de exploração (MELO \& MASSULA, 2003).

A existência de demanda por pessoas traficadas para desenvolverem determinadas atividades, bem como a existência de pessoas que se arriscam a aceitar propostas de trabalho em outras localidades, muitas vezes com poucas informações a seu respeito, têm uma ligação próxima (KEMPADOO, 2005).

O tipo de atividade em que a vítima se engajou, seja licita, ilícita, moral ou imoral não se mostra relevante para determinar se seus direitos foram ou não violados. O que está em questão é se há 
violação nos exercícios de seus direitos, constrangimento de vontade e violação corporal (GAATW, 1997).

Como destacado por Agostín (2005, p. 7), questões sobre suprimento e demanda não podem ser analiticamente separadas, e ambas são caracterizadas, ou até determinadas, por um conjunto complexo e interligado de fatores políticos, sociais e institucionais.

O Escritório do Alto Comissário das Nações Unidas para os Direitos Humanos, o Relator Especial da ONU sobre violência contra Mulheres e a Organização Internacional de Migração (IOM), através de todas as definições já anotadas de tráfico, reconheceram o problema como sendo uma ofensa aos Direitos Humanos, pois envolve o trabalho forçado, servidão e escravidão, não se limitando apenas à questão da prostituição (GAATW, 1997).

Os serviços de pessoas traficadas são invariavelmente explorados/consumidos em setores em que o Estado concede pouca ou nenhuma proteção a trabalhadores imigrantes desqualificados e/ou outras categorias de pessoas exploradas (como esposas, crianças adotadas, pedintes); e em que trabalhadores ou outros grupos explorados têm pouca ou nenhuma oportunidade de se organizarem coletivamente para se protegerem de abuso e exploração. Esses setores não existem simplesmente, mas são criados por meio de uma combinação de ação e inação de parte de atores estatais e outros grupos de interesses (ALMEIDA, 2004).

Mas foi através do Protocolo para Prevenir, Suprimir, e Punir o Tráfico de Pessoas, especialmente Mulheres e Crianças, realizado na cidade de Palermo, na Itália - que suplementou a convenção da ONU contra o Crime Organizado Transnacional adotada em outubro de 2000 e ratificada pelo então presidente Luiz Inácio Lula da Silva em março de 2004 que foi trazida a primeira definição internacional aceita de Tráfico de Seres Humanos:

a) "Trafico de pessoas" deve significar o recrutamento, transporte, transferência, abrigo ou recebimento de pessoas por meio de ameaça ou uso da força ou outras formas de coerção, de rapto, de fraude, de engano, do abuso de poder ou de uma posição de vulnerabilidade ou de dar ou receber pagamentos ou benefícios para obter o consentimento para uma pessoa ter controle sobre a outra, para o propósito de exploração, inclui, no mínimo a exploração da prostituição, ou outras formas de exploração sexual, trabalho ou serviços forçados, escravidão ou praticas análogas à escravidão, servidão ou a remoção de órgãos.

b) O Consentimento de uma vítima de tráfico de pessoas para desejada exploração definida no subparágrafo a) 
deste artigo deve ser irrelevante onde qualquer um dos meios definidos no subparágrafo a) tenham sido usados.

c) $\mathrm{O}$ recrutamento, transporte, transferência, abrigo ou recebimento de uma criança para fins de exploração devem ser considerados "Trafico de Pessoas" mesmo que não envolvam nenhuns dos meios definidos no subparágrafo a) deste artigo.

d) "Criança" deve significar qualquer pessoa com menos de 18 anos de idade (CASTILHO, 2007).

As autoras salientam que quase não existe demanda por pessoas traficadas para serem exploradas em setores em que os trabalhadores estão organizados, os contratos são bem estabelecidos e as rotinas de trabalho são monitoradas. Segundo Almeira (2004, p. 8), a demanda pelo trabalho de pessoas traficadas é frequentemente encontrada em contexto que é socialmente imaginado por não envolver relações de trabalho. Por exemplo, aqueles que exploram trabalho infantil frequentemente não reconhecem as crianças como empregados ou eles como empregadores e escondem o que é uma relação de exploração de trabalho atrás de relações de parentesco fictícias ou alguma outra forma de paternalismo. Isso também se pode aplicar em relação ao trabalho envolvendo adultos. Por sua vez, "prostituta" é frequentemente tomada para referir uma categoria de pessoa (uma sub- pessoa) mais do que uma categoria de trabalhador, e assim não pode ser imaginada como um sujeito de direitos.

Essa definição incorporou em seu conteúdo sugestões feitas pelo Alto Comissariado da ONU sobre Direitos Humanos (OHCHR), por OSCs de Direitos Humanos e por diversos especialistas ouvidos em diferentes momentos do processo de consulta da adoção da Convenção de Palermo (CASTILHO, 2007).

O protocolo contém a primeira definição aceita internacionalmente sobre o tráfico, reconhecendo a prostituição voluntária e forçada, não se abstendo na forma em que os Estados Partes se referem à prostituição em suas leis domésticas, focalizando a sua prática forçada e outros crimes que envolvam a força ou a coerção (CASTILHO, 2007).

Kempadoo (2004, p. 8), destacam, ainda, que trabalhadores imigrantes ilegais ou irregulares são muito mais vulneráveis à exploração por grupos de traficantes de pessoas, em face do desconhecimento da língua e do local para onde são levados. Muitas vezes aceitam propostas de trabalho em outros locais devido à necessidade de ganhar dinheiro e às condições socioeconômicas que estão vivenciando. Um dos recursos utilizados para subjugar esses 
trabalhadores são os débitos, o confinamento, a força e os tratamentos violentos.

Um dos seus principais pontos foi o que tratou dos abusos cometidos durante o curso do tráfico, estando esses fatos previstos nos direitos nacionais ou no direito internacional (CASTILHO, 2007).

Assim, atividades como serviços gerais, serviços domésticos, trabalhos na agricultura, na construção civil, nas indústrias e manufaturas, na prostituição, entre outras, tendem a ser aquelas nas quais são exploradas pessoas traficadas, em várias regiões do mundo (KEMPADOO, 2005).

Para Damásio (2002) a definição foi mais além, procurando em primeiro lugar garantir que as vítimas do tráfico não sejam tratadas como criminosas, mas sim como pessoas que sofrem sérios abusos. Devendo, nesse sentido, ser criado pelos Estados Partes serviços de assistência e mecanismos de denúncia.

Exploração da prostituição de outrem ou outras formas de exploração sexual. A expressão "exploração da prostituição de outrem ou outras formas de exploração sexual" é criticada por diversos autores em face da sua imprecisão, o que não auxilia em nada a compreensão desse tipo de exploração, principalmente por se referir a uma atividade específica, a prostituição, quando o intuito seria desvincular o tráfico de qualquer atividade laboral, para compreendê-lo como uma conduta na qual se usam meios fraudulentos para explorar alguém (KEMPADOO, 2005).

\section{TRÁFICO INTERNACIONAL DE MULHERES}

Leal (2002) relatou em sua pesquisa que, de acordo com a ONU e a Federação Internacional Helsinque de Direitos Humanos, 75.000 brasileiras estariam sendo obrigadas a se prostituir nos países da União Europeia.

Segundo a OIM - Organização Internacional da Migração (apud SILVA, 2007), quatro milhões de pessoas são traficadas por ano contra a própria vontade para trabalhar em alguma forma de escravidão. O Relatório do Departamento de Estado dos EUA de 2.000 afirmou que entre 45.000 e 50.000 mulheres e crianças traficadas ingressam no país por ano.

Relatório divulgado a propósito do Dia Internacional da Mulher de 2001 pelo órgão executivo da União Europeia (UE) destacou que 120 mil mulheres e crianças são introduzidas ilegalmente, por ano, na UE. A maior parte é do Leste Europeu. Há estimativas de que os bandos transportam até 500 mil mulheres para a 
UE a cada ano. A meta do tráfico de pessoas é não somente a prostituição, mas também a exploração de mão-de-obra sob condições semelhantes às da escravidão, diz o relatório (apud SILVA, 2007)

\section{LEGISLAÇÃO SOBRE O TRÁFICO DE PESSOAS}

\section{O artigo 231 do Código Penal} Brasileiro, com a redação trazida pela Lei $n^{\circ} 11.106 / 2005$, assim define o crime de tráfico internacional de pessoas: "Promover, intermediar ou facilitar a entrada, no território nacional, de pessoa que venha a exercer a prostituição ou a saída de pessoa para exercê-la no estrangeiro".

Observando a legislação vigente em território nacional, nota-se que, apesar de não haver uma legislação especifica para o crime, ele acaba por estar implícito em outros tipos penais, como por exemplo: - Trafico de trabalhadores (Art. 2006 e 2007 do Código Penal Brasileiro), trafico internacional de mulheres (Art. 231 do Código penal Brasileiro), redução a condição análoga a de escravo (Art. 149) (apud PINTO LEAL, 2007).

Os tipos penais mais freqüentes na ocorrência de trafico de pessoas são: Art. 297 - Falsificação de documento publico; Art. 298 - Falsificação de documento particular; Art. 299- Falsidade ideológica.

De acordo com Costa (2004), “a legislação brasileira não está de plena conformidade com a definição do Protocolo para a Prevenção, Repressão e Punição do Tráfico de Pessoas, especialmente Mulheres e Crianças, Adicional à Convenção do Crime Organizado Transnacional (Convenção de Palermo), segundo a qual o tráfico consiste em recrutar, transportar, transferir, alojar ou acolher pessoas, mediante ameaça, violência física ou a outras formas de coação, sequestro, fraude, engano, abuso de autoridade ou à situação de vulnerabilidade, ou ainda mediante entrega ou aceitação de pagamento ou benefício para obter o consentimento de uma pessoa que tenha autoridade sobre outra, para fins de exploração." Nos termos do artigo $3^{\circ}$ do Protocolo, "a exploração inclui, no mínimo, a exploração da prostituição de outrem ou outras formas de exploração sexual, o trabalho ou serviços forçados, escravatura ou práticas similares à escravatura, a servidão ou a remoção de órgãos."

Um aspecto importante do Protocolo é a preocupação em assegurar proteção à vítima, inexistente nas convenções internacionais anteriores. Tal proteção implica, por exemplo, em 
permitir a permanência da vítima no país de destino, caso se verifique risco de vida ou de revitimização no país de origem, e assistência em caráter integral. Para o Nederstig e Almeida, (2007),

a proteção às vítimas parece ser um objetivo óbvio, mas na prática, elas são, muitas vezes, tratadas como criminosas que violaram a lei da migração". Observa, ainda, que "muitas delas, mesmo quando livres, não conseguem escapar da escravidão mental a que foram condicionadas.

Em Silva (2007), encontra-se que, com relação ao trabalho escravo/degradante no Brasil, algumas importantes medidas vêm sendo implementadas, onde o foco é reprimir, proteger e oferecer assistência às vitimas. Destaque para a explicação de que há participação de setores da sociedade civil nesse processo. Uma vez que exercer a cidadania e o controle democrático também constituem fatores decisivos no combate ao tráfico, além de denúncias às autoridades serem efetuadas por parte de quem souber da existência ou potencial acontecimento da situação de exploração.

Se faz necessário ressaltar que o Código Penal evoluiu quando da publicação da Lei $\mathrm{n}^{\circ} 11.106$, de 28 de março de 2005, ao alterar o artigo 231, cuja redação original definia o tipo penal como "Promover ou facilitar a entrada, no território nacional, de mulher que nele venha exercer a prostituição, ou a saída de mulher que vá exercê-la no estrangeiro: Pena - reclusão, de três a oito anos".

Se, no contexto do trabalho degradante as evidências apontam para condições precárias de vida e saúde, violência e maus-tratos (SILVA, 2007) com relação aos trabalhadores vitimados, com relação às mulheres em situação de tráfico a escassa literatura existente aponta para caminhos parecidos: falta de cuidado com a saúde dessas mulheres, abusos de substâncias químicas lícitas e ilícitas e a proliferação de Doenças Sexualmente Transmissíveis.

A Organização Internacional do Trabalho (OIT) faz uma separação conceitual clara entre o trabalho escravo com finalidade de exploração econômica subdividido em rural e urbano - e o trabalho para fins de exploração sexual. Entende-se que há variações e peculiaridades de um para o outro, e tratálos individualmente é um passo importante ao enfrentamento de ambos.

$\mathrm{O}$ aperfeiçoamento da legislação brasileira no que concerne ao enfrentamento ao tráfico de pessoas deve ter em conta o disposto no Protocolo contra o Contrabando de Migrantes por Terra, Mar e Ar (CASTILHO, 2000), promulgado pelo Decreto $\mathrm{n}^{\circ} 5.016$, de 12 
de março de 2004, o qual, em seu artigo $3^{\circ}$, alínea 'a', define o tráfico de migrantes como sendo " a intermediação da entrada ilegal de uma pessoa em um Estado do qual não tem nacionalidade nem status de residência permanente, com o objetivo de obter, direta ou indiretamente, benefícios financeiros ou materiais de outro tipo".

\section{CONCLUSÃO}

O tráfico de pessoas não é um tema recente, nem um fenômeno simples de ser compreendido, uma vez que possui características únicas e raízes profundas na miséria e exploração de países de terceiro mundo.

A rota do tráfico de seres humanos é a rota do dinheiro, onde as pessoas mais humildes são presas fáceis. Em busca de condições melhores de vida, se dispõem a sair de seu pais influenciadas por aliciadores, em busca de promessas falsas, muitas vezes promessas de trabalho onde ganhariam muito dinheiro em pouco tempo, e posteriormente, vêem que essa realidade é irreal, sendo forçadas a realizar trabalhos forçados, extremamente mal remunerados e em péssimas condições.

Outra face do tráfico de pessoas, é a exploração sexual, onde mulheres traficadas são obrigadas a se prostituir temendo pela própria vida. Com a realização do presente trabalho foi possível concluir que o tráfico de pessoas está intimamente ligado a questões sócio culturais, ao qual a política e a própria sociedade, muitas vezes é complacente com tal situação, e as políticas de combate ao tráfico de seres humanos, são um passo importante, mas, não totalmente efetivos.

\section{REFERÊNCIAS}

ABREU, Maria Luiza Marqueda. El tráfico sexual de personas. Valência: Tirant lo Blanch, 2001.

AGOSTÍN, Laura. Migrants in the mistress's house: other voices in the 'trafficking' debate. Social Politics, Oxford, v. 12, n. 1, 2005.

ALIANCE AGAINST TRAFFIKING IN WOMEM, GAATW. Regional meeting on trafficking in womem, forced labor, and slavery-like practice in Asia and Pacific. BangloK, Thailand: GAATW, 1997.

ALVES, A.C. Novo contrato de emprego: parassubordinação trabalhista. São Paulo: LTr, 2004.

ALMEIDA, Suely Souza de. Violência e Direitos Humanos no Brasil. In Praia Vermelha, no 11, RJ, UFRJ. 2004.

BRASIL. Decreto $\mathrm{n}^{\circ}$ 5.017, de 12 de março de 2004. Disponível em: http://www.planalto.gov.br/ccivil_03/_ato2 004-2006/2004/decreto/d5017.htm. Acesso em 16 de jun. 2015.

BRASIL. Lei $\mathrm{n}^{\circ} 11.106$, de 28 de março de $2005 . \quad$ Disponível em: 
http://www.planalto.gov.br/ccivil_03/_ato2 004-2006/2005/lei/111106.htm. Acesso em 16 de jun. 2015.

CASTILHO, Ela Wiecko V. de. Tráfico de Pessoas: da convenção de Genebra ao Protocolo de Palermo. In: Cartilha Ministério da Justiça: Política Nacional de Enfrentamento ao Tráfico de Pessoas. Brasília: 2007. Disponível em: .pgr.mpf.gov.br/publicacoes/docs_artigos/a rtigo_trafico_de_pessoas.pdf; Acesso em 14 de jun. 2015.

COSTA, Paulo. Trafico de Pessoas. Algumas considerações legais. Instituto Superior de Economia e Gestão, Universidade Técnica de Lisboa, 2004.

GALLAGHER, Anne. Trafficking, smuggling and human rights: tricks and treaties. Forced Migration Review , Oxford, n. 12, 2002

JESUS, Damásio de. Trafico internacional de mulheres e crianças - Brasil. Editora Saraiva. 2002

LEAL, Maria Lúcia; LEAL, Maria de Fátima P. (Orgs.). Pesquisa sobre tráfico de mulheres, crianças e adolescentes para fins de exploração sexual comercial: relatório nacional. Brasília: CECRIA; PESTRAF, 2002.

MELO, Mônica de; MASSULA, Letícia. Tráfico de Mulheres: Prevenção, Punição e Proteção. Cartilha elaborada por ocasião do Seminário Internacional sobre Tráfico de Mulheres realizado em outubro de 2003. Disponível na Internet:http://www.centrodandara.org.br/S ubsidios/Tr\%E1fico\%20de\%20Mulheres\% 20\%20Preven\%E7\%E3o\%20Puni\%E7\%E 3o\%20e\%20Prote\%E7\%E3o.htm Acesso em 14 de ago. 2014.
KEMPADOO, Kamala. Mudando o debate sobre o tráfico de mulheres. Cadernos Pagu, Campinas, n. 25, jul./dez. 2005.

NEDERSTIG, Frans; ALMEIDA, Luciana Campello R. DANO COLATERAL: Impacto das medidas anti-trafico nos direitos humanos no mundo, arquivo em DVD, GAATW, Bangkok, 2007;

NOGUEIRA, Charo. Una de cada tres mujeres ha sufrido malos tratus o algún tipo de abuso. El país, Madrid, 21/09/2000.

PISCITELLI, Adriana. 'Gringos' nos trópicos: gênero e nacionalidade no marco do turismo sexual em Fortaleza. In: CNPD - Migrações internacionais : contribuições para a política. Brasília, 2001.

PINTO LEAL, Maria Lúcia; PINTO LEAL, Maria de Fátima; COIMBRA LIBORIO, Renata Maria. Tráfico de Pessoas e Violência Sexual, Ed. Violes, Brasília, 2007

ORGANIZAÇÃO DAS NAÇÕES UNIDAS. Protocolo Adicional à Convenção das Nações Unidas contra a Criminalidade Organizada Transnacional relativo à Prevenção, à Repressão e à Punição do Tráfico de Pessoas, em especial de Mulheres e Crianças. Disponível em: http://sinus.org.br/2014/wpcontent/uploads/2013/11/OIT-Protocolode-Palermo.pdf. Acesso em 17 de jun. 2015.

RIBEIRO, Vanessa. Tráfico de Pessoas, Políticas públicas e o $4^{o}$ Poder. Universidade Católica do Salvador. Disponível em: http://www.anpuh.uepg.br/historiahoje/vol 2n6/Vanessa\%20Cavalcanti.pdf Acesso em 17 de set.. 2014.

SHECARIA, Sergio Salomão; SILVEIRA, Renato de Mello Jorge. $O$ Tráfico 
Internacional de Mulheres e Crianças. Disponível em: <http://www.direitopenal.adv.br. Acesso em 17 de mar. 2015.

SILVA, M. A. A questão social, vulnerabilidades e fragilidades do sistema de proteção social no Brasil. In: Violes (Org.) Tráfico de pessoas e violência sexual. Brasília: UnB, 2007. 